Proceedings

\title{
"New" Solutions to the Problem of Poorly Soluble Drugs - The Role of "Green", Anti-Crystal Engineering ${ }^{\dagger}$
}

\author{
Lidia Tajber ${ }^{1, *}{ }^{,}$Hanah Mesallati ${ }^{1}$, Julija Zotova ${ }^{1}$, Zaneta Wojnarowska ${ }^{2}$ and Anita Umerska ${ }^{1}$ \\ 1 Trinity College Dublin, School of Pharmacy and Pharmaceutical Sciences, College Green, Dublin 2, Ireland; \\ mesallah@tcd.ie (H.M.); zotovaj@tcd.ie (J.Z.); umerskaa@tcd.ie (A.U.) \\ 2 Institute of Physics, University of Silesia, SMCEBI, 75 Pulku Piechoty 1A, 41-500 Chorzow, Poland; \\ zaneta.wojnarowska@smcebi.edu.pl \\ * Correspondence: lidia.tajber@tcd.ie \\ + Presented at the 1st International Electronic Conference on Pharmaceutics, 1-15 December 2020; Available \\ online: https://iecp2020.sciforum.net/.
}

Published: date

\begin{abstract}
One of the areas of pharmaceutical research into oral solid dosage forms that has seen a significant surge in interest lies in the optimisation of physical forms of active pharmaceutical ingredients (APIs). Alterations of the solid form of APIs aim at improving a drug's solubility, permeability and therefore, bioavailability. Research has led to the development of various crystalline multicomponent API systems, such as salts and co-crystals, with the recent emphasis on the manufacture of non-crystalline or weakly crystalline materials such as amorphous solid dispersions or less traditional forms such as ionic liquids and deep eutectic mixtures. To design such systems, the principles of anti-crystal engineering might be applied, whereby instead of purposely forming a crystalline, multicomponent system based on specific synthon interactions, the opposite is accomplished and a mixture with a weak or no crystallisation potential develops. For pharmaceutical applications, such a mixture will have a very desirable property - non-existent or very low crystal lattice (energy) allowing the drug molecules to be readily available for transport and absorption. This work will concentrate on the mechanochemical, green approach to anti-crystal engineering. The concept of amorphous polymeric salts will be presented, with ball mill facilitating the proton transfer between the API and the polymer leading to an increase in solubility and biological activity of the drug. Another example will show how mechanochemistry can facilitate the formation of ionic liquids and (deep) eutectic mixtures with studies on how the counterion/coformer can manipulate the properties of the resulting phases.
\end{abstract}

Keywords: active pharmaceutical ingredient; multicomponent system; anti-crystal engineering; mechanochemistry; polymeric salt; ionic liquid

Publisher's Note: MDPI stays neutral with regard to jurisdictional claims in published maps and institutional affiliations.

(C) 2020 by the authors; licensee MDPI, Basel, Switzerland. This article is an open access article distributed under the terms and conditions of the Creative Commons by Attribution (CC-BY) license (http://creativecommons.org/licenses/by/4.0/). 